\title{
Mental Foramen - A Morphological Evaluation of Dry Adult Human Mandible in Indian Population
}

\author{
Keshav Krishna ${ }^{1}$, Nand Kishor Karmali ${ }^{2}$ \\ ${ }^{1}$ Tutor, Department of Anatomy, Phulo Jhano Medical College, Dumka, Jharkhand \\ ${ }^{2}$ Assistant Professor, Department of Anatomy, Phulo Jhano Medical College, Dumka, Jharkhand \\ Corresponding Author: Keshav Krishna
}

DOI: https://doi.org/10.52403/ijrr.20220202

\begin{abstract}
Background: Mental foramen is an important anatomical and surgical landmark. Mental nerve and vessels emerge from it. Knowledge of variations in morphology of mental foramen in various populations is important, as it is a common site for regional anaesthesia in various dental and maxillofacial surgical procedures.

Aim: Aim of present study is to look into the morphological differences in mental foramen of dry adult mandibles in Indian.

Material and Method: Forty-one (41) dry adult human mandible of known sex obtained from the Department of Anatomy, Phulo-Jhano Medical College Dumka, Jharkhand and students of this institution were studied. Shape, direction and position of mental foramen were visually assessed. Distance from mental foramen to symphysis menti and distance from alveolar crest to mental foramen was measured.

Results: Oval shape was the most common type. Position below second premolar tooth was most common. Direction of opening of MF was postero-superior in $88.6 \%$ and in the rest, it was antero-superior.
\end{abstract}

Conclusion: This study reaffirms that morphological variations of mental foramen do exist between different populations and knowledge of these variations is important for various anaesthetic and surgical procedures.

Key Words: Morphology, Morphometry, Mental Foramina, Mandible, Mental Nerve

\section{INTRODUCTION}

Mental foramen (MF) is a small opening in the anterolateral aspect of the mandible. It is most often present bilaterally. It is the anterior end of the mandibular canal. The posterior end of the mandibular canal present on the inner aspect of mandible, termed mandibular foramen. Mandibular canal gives passage to inferior alveolar nerve and vessels. Near to the mental foramen the inferior alveolar nerve divides into mental nerve and incisive nerve. Mental nerve and mental vessels emerge from mental foramen. This nerve innervates the skin and soft tissues of the adjacent regions. The position of the mental foramen is usually described at a point on the middle of vertical line between first and second inferior premolars in adults, roughly $2.5 \mathrm{~cm}$ lateral to symphysis menti and 1.25 $\mathrm{cm}$ above the lower border of mandible ${ }^{[1,2]}$. Position of MF varies with age and sex ${ }^{[1,2]}$. Sometimes a smaller foramen is seen adjacent to it, termed as accessory mental foramen (AMF). Rarely mental foramina may be absent.

Aim of present study is to look into the morphological differences in mental foramen of dry adult mandibles in Indian. Knowledge of morphology of mental foramen is very important as it is the site of nerve block for anaesthesia during various maxillofacial reconstructive surgery and dental procedures. It is also used as a reference point for surface marking of mandibular canal for various surgical procedures $^{[1,2]}$. 

population.

\section{MATERIAL AND METHODS}

This study was conducted on 41 dry adult human mandible of known sex. Mental foramens on both the sides of mandible were studied. Mandibles were obtained from the Department of Anatomy, Phulo Jhano Medical College, Dumka, Jharkhand and from students of this college. Mental foramen was visually assessed for its shape and was described as either oval or rounded. Mandible was placed on a horizontal surface and perpendicular lines to it were drawn along first premolar (Position I: P-I), between first premolar and second premolar (Position II: P-II), along second premolar (Position III: P-III) and between second premolar and first molar interdental space (Position IV: P-IV). Direction of opening of MF was also assessed and classified as either antero-superior or postero-superior. Various morphometric measurements were recorded using vernier calliper. Distance between symphysis menti to anterio border of MF was measured. Distance between alveolar crest and superior margin of MF was also measured. Horizontal and vertical diameter of MF was measured.

\section{RESULT}

Mental foramen was present bilaterally in all the 41 mandibles. Accessory mental foramen was present in 3 mandibles and was present unilaterally. Both on the right and left side, most common shape was oval $-59.5 \%$ and $61 \%$ respectively. Regarding position, on the right side most commonly, observed position was on the longitudinal line along the second premolar tooth i.e., position III $78 \%$, followed by position II-15 $\%$ and position IV-7\%. On the left side most, common observed position was on the longitudinal line along the second premolar tooth i.e., position III- 84\%, followed by position II-14 \% and position IV-2\%. Direction of opening of MF was posterosuperior in $88.6 \%$ and in the rest, it was antero-superior.

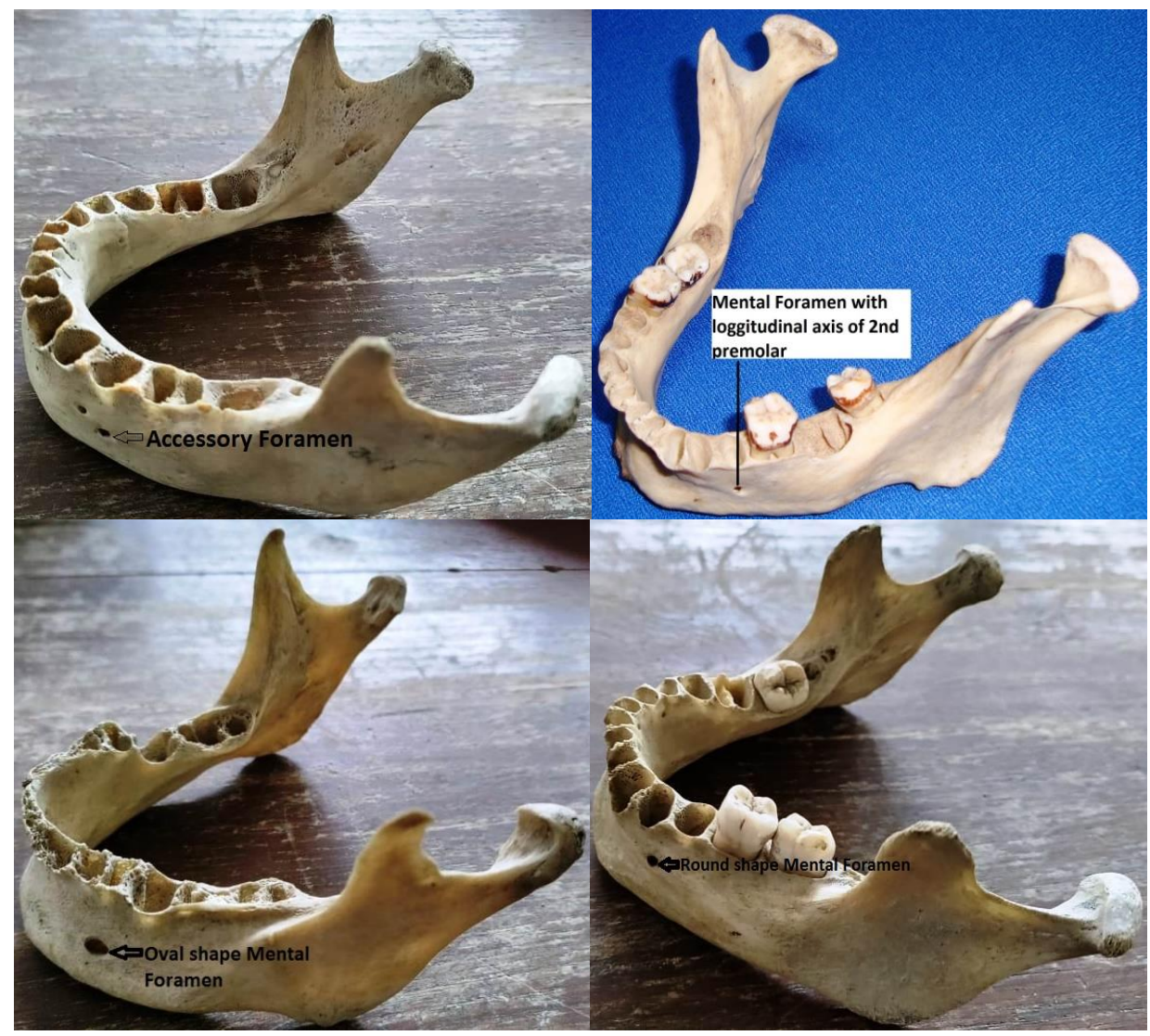

Figure 1: Various morphological features of Mental Foramen 

population.

Average distance from symphysis menti to anterior margin of MF was 26.07 $\mathrm{mm}$ on right side and 25.36 on left side. Average of measurement of distance from upper border of MF to alveolar crest was $11.54 \mathrm{~mm}$ and $12.08 \mathrm{~mm}$ on right and left side respectively. Mean horizontal diameter of MF on right and left sides were $3.08 \mathrm{~mm}$ and $3.34 \mathrm{~mm}$ respectively. Mean vertical diameter of MF on right and left sides were $2.36 \mathrm{~mm}$ and $2.16 \mathrm{~mm}$ respectively.

\begin{tabular}{|l|l|l|}
\multicolumn{4}{c}{ Table 1: Shapes of Mental Foramen } \\
\hline \multirow{2}{*}{ Sides } & Shapes (\%) & Round \\
\cline { 2 - 3 } & Oval & $39.02(\mathrm{n}=16)$ \\
\hline Right & $60.97(\mathrm{n}=25)$ & $41.46(\mathrm{n}=17)$ \\
\hline Left & $58.53(\mathrm{n}=24)$ & n- means number
\end{tabular}

Table 2: Position of Mental Foramen

\begin{tabular}{|l|l|l|l|l|}
\hline \multirow{2}{*}{ Sides } & \multicolumn{4}{|l|}{ Positions (\%) } \\
\cline { 2 - 5 } & P-I & P-II & P-III & P-IV \\
\hline Right & - & $15 \%$ & $78 \%$ & $7 \%$ \\
\hline Left & - & $84 \%$ & $14 \%$ & $2 \%$ \\
\hline
\end{tabular}

\section{DISCUSSION}

Knowing the applied importance of shape, size, position, direction and morphometric measurements related to mental foramen the result of this present study was compared with other such studies in India and other countries. Ethnic variations relating to these variables have been described in earlier literatures. Variations may also be due to different food and chewing habits, which have effect on morphology of mandible and MF.

In the present study the most common shape observed was oval. This finding was consistent with some other such studies, but varied from few of them e.g., Singh R et al. and S Kumar N et al. Sing R et al. reported round shape as most common, $94 \%$ and $87 \%$ in right and left side respectively. $\mathrm{S}$ Kumar $\mathrm{N}$ et al. reported round shape as most common, $95 \%$.

In the present study the most common position of mental foramen was $\mathrm{P}$ III i.e., below second mandibular premolar. This finding is consistent with most other such studies in India except for few e.g., Balakrishnan YA et al. reported P-III (52\%) on left side and P-II (48\%) on right side as most common position. The findings of present study are consistent with other such studies in Korean, Malaysian and Sri Lankan population, but differed from a study on Turkish population (Yeşilyurt et al.) which reported P-II as most common position, $55.7 \%$ and $61.4 \%$ on right and left sides respectively and also differs from standard text books which describe P-II as most common position. Direction of opening of $\mathrm{MF}$ was postero-superior in $88.6 \%$ of samples.

Average distance between symphysis menti and anterior border of mental foramen was $26.07 \mathrm{~mm}$ and 25.36 $\mathrm{mm}$ on right and left sides respectively. While average distance between alveolar crest and superior margin of mental foramen was $11.544 \mathrm{~mm}$ and $12.08 \mathrm{~mm}$ on right and left side respectively.

Table 3: Comparison of shapes of Mental Foramen

\begin{tabular}{|l|l|l|l|l|}
\hline \multirow{2}{*}{ Authors } & \multirow{2}{*}{ Year } & \multirow{2}{*}{ Side } & \multicolumn{2}{|l|}{ Shapes (\%) } \\
\cline { 3 - 5 } & & & Rounded & Oval \\
\hline \multirow{2}{*}{ Singh R. et al. ${ }^{[3]}$} & \multirow{2}{*}{2010} & Right & 94 & 6 \\
\cline { 3 - 5 } & & Left & 87 & 13 \\
\hline Budhiraja V et al. $^{[4]}$ & 2013 & - & 25.7 & 74.3 \\
\hline Roy PP et al. $^{[5]}$ & 2014 & - & 34.67 & 53.3 \\
\hline S Kumar N et al. $^{[6]}$ & 2019 & - & 95 & 5 \\
\hline Yeşilyurt et al. & & \\
\hline \multirow{2}{*}{ Present Study } & & & 34.5 & 65.5 \\
\cline { 3 - 5 } & & Right & 39.02 & 60.97 \\
\cline { 3 - 5 } & & Left & 41.46 & 58.53 \\
\hline
\end{tabular}

Table 4: Comparison of various positions of Mental Foramen in percentage $(\%)$

\begin{tabular}{|l|l|l|l|l|l|l|}
\hline \multicolumn{7}{|c|}{ Positions } \\
\hline Authors & Side & P-I & P-II & P-III & P-IV & Population \\
\hline \multirow{2}{*}{ Yeşilyurt et al. $^{[7]}$} & Right & - & 55.7 & 34.3 & 4.3 & \multirow{2}{*}{ Turkish } \\
\cline { 2 - 7 } & Left & - & 61.4 & 25.7 & 5.7 & \\
\hline Singh R et al. ${ }^{[3]}$ & Either & 2.1 & 17.8 & 68.8 & 11.52 & \multirow{2}{*}{ Indian } \\
\hline \multirow{2}{*}{ Budhiraja V et al. ${ }^{[4]}$} & Right & 3.8 & 20.0 & 61.0 & 14.3 & \multirow{2}{*}{ Northern Indian } \\
\cline { 2 - 7 } & Left & 2.9 & 20.9 & 59.1 & 15.2 & \\
\hline Roy PP et al. ${ }^{[5]}$ & Either & & 23.33 & 52 & & \multirow{2}{*}{ Indian } \\
\hline \multirow{2}{*}{ Balakrishnan YA et al. ${ }^{[8]}$} & Right & 8 & 48 & 32 & 12 & \multirow{2}{*}{ Southern India } \\
\cline { 2 - 6 } & Left & 8 & 24 & 52 & 12 & \\
\hline Ilayperuma et al. $^{[9]}$ & Either & - & 26.47 & 52.94 & - & Srilankan \\
\hline Kim et al. ${ }^{[10]}$ & Either & - & 26.8 & 64.3 & - & Korean \\
\hline Ngeow et al. ${ }^{[1]}$ & Either & - & 19.6 & 69.2 & - & Malaysia \\
\hline \multirow{2}{*}{ Present study } & Right & & 15 & 78 & 07 & \multirow{2}{*}{ Indian } \\
\cline { 2 - 6 } & Left & & 14 & 84 & 02 & \\
\hline
\end{tabular}


Keshav Krishna et.al. Mental foramen- a morphological evaluation of dry adult human mandible on Indian population.

Table 5: Comparison of various mandibular parameters related to Mental Foramen

\begin{tabular}{|c|c|c|c|}
\hline Authors & Side & $\begin{array}{l}\text { Distance } \\
\text { between } \\
\text { symphysis menti } \\
\text { to anterio } \\
\text { border of } \mathrm{MF}\end{array}$ & $\begin{array}{l}\text { Distance } \\
\text { between } \\
\text { alveolar crest } \\
\text { and superior } \\
\text { margin of } \mathrm{MF}\end{array}$ \\
\hline \multirow{2}{*}{$\begin{array}{l}\text { Yesilurt et al. }{ }^{[7]} \\
\text { (Turkey) }\end{array}$} & Right & 19.18 & 10.5 \\
\hline & Left & 19.37 & 10.64 \\
\hline $\begin{array}{l}\text { Singh et al. } \\
\text { (North India) }\end{array}$ & $\begin{array}{l}\text { Either } \\
\text { side }\end{array}$ & 23.6 & 15.3 \\
\hline \multirow{2}{*}{$\begin{array}{l}\text { Balakrishnan et } \\
\text { al. }[8] \text { (South } \\
\text { India) }\end{array}$} & Right & 26.28 & 11.93 \\
\hline & Left & 25.45 & 12.26 \\
\hline \multirow{2}{*}{ Present study } & Right & 26.07 & 11.54 \\
\hline & Left & 25.36 & 12.08 \\
\hline
\end{tabular}

\section{CONCLUSION}

Variations in morphology and morphometry of mental foramen are well documented. This study reaffirms that variations do exist, and knowledge of these variations is important for an uneventful successful surgical procedure on mandible such as reconstructive facial surgery and for localising the neurovascular bundle during local anaesthesia. Larger sample size is needed for further evaluation of data.

\section{Acknowledgement: None}

\section{Conflict of Interest: None}

\section{Source of Funding: None}

\section{Ethical Approval: Approved}

\section{REFERENCES}

1. Susan Standring. Gray's Anatomy, The Anatomical Basis of Clinical Practice, Forty Second edition

2. Singh, Vishram 1. Textbook of Anatomy: Head, Neck and Brain, Vol 3, 3rd Updated Edition, Elsevier Health Sciences.

3. Singh R, Srivastav AK. Study of position, shape, size and incidence of mental foramen and accessory mental foramen in Indian adult human skulls. Int JMorphol. 2010; 28(4):1141-6

4. Budhiraja V, Rastogi R, Lalwani R, Goel P, Chandra S. Study of position, shape, and size of mental foramen utilizing various parameters in dry adult human mandibles from North India. International Scholar Research Notices, 2012, 1-5.

5. Priya P Roy, Ambali M P, Doshi M A, Jadhav $S$ D. Variation In The Position Shape And Direction Of Mental Foramen In Dry Mandible. Int J Anat Res 2014; 2(2): 418-20.

6. Naveen Kumar S, Ashok Kumar M. Morphometric Study of Mental Foramen in Mandibles of Telengana Region. Indian $\mathbf{J}$ Anat. 2019(8):45-48

7. Yesilyurt H, Aydinilioglu A, Kavakli A, Ekinci N, Eroglu C, Hacialiogullari M, et al. Local differences in the position of the mental foramen. Folia Morphol 2008; 67(1):32-35.

8. Yogi Anupkumar Balakrishnan, S. Vikram, Chitra Prakash Rao, SanjayKumar B Revankar. Position Of Mental Foramen In Dry Human Mandibles And Its Significance. Int J Anat Res 2018;6(2.2): 5228-5232. DOI: 10.16965/ijar.2018.162

9. Ilayperma I, Nanayakkara G, Palahepitiya N. Morphometric analysis of mental foramen in adult Srilankan mandibles. Int J Morphol 2009; 27(4):1019-24.

10. Kim IS, Kim SG, Kim YK, Kim JD. Position of the mental foramen in a Korean population: A clinical and radiographic study. Implant Dentistry 2006;15(4):404-11.

11. Ngeow WC, Yuzawati. The location of the mental foramen in a selected Malay population. J Oral Sci 2003; 45(3):171-5.

How to cite this article: Keshav Krishna, Nand Kishor Karmali. Mental foramen- a morphological evaluation of dry adult human mandible in Indian population. International Journal of Research and Review. 2022; 9(2): 69. DOI: https://doi.org/10.52403/ijrr.20220202 